\title{
THE GROWING IMPORTANCE OF COGNITIVE SKILLS IN WAGE DETERMINATION
}

\author{
Richard J. Murnane \\ John B. Willett \\ Frank Levy
}

Working Paper No. 5076

\section{NATIONAL BUREAU OF ECONOMIC RESEARCH 1050 Massachusetts Avenue \\ Cambridge, MA 02138 \\ March 1995}

This paper is part of NBER's research program in Labor Studies. Any opinions expressed are those of the authors and not those of the National Bureau of Economic Research.

(C) 1995 by Richard J. Murnane, John B. Willett and Frank Levy. All rights reserved. Short sections of text, not to exceed two paragraphs, may be quoted without explicit permission provided that full credit, including $\odot$ notice, is given to the source. 
NBER Working Paper \#5076

March 1995

\title{
THE GROWING IMPORTANCE OF COGNITIVE SKILLS IN WAGE \\ DETERMINATION
}

\begin{abstract}
Using data from two longitudinal surveys of American high school seniors, we show that basic cognitive skills had a larger impact on wages for 24-year-old men and women in 1986 than in 1978. For women, the increase in the return to cognitive skills between 1978 and 1986 accounts for all of the increase in the wage premium associated with post-secondary education. We also show that high school seniors' mastery of basic cognitive skills had a much smaller impact on wages two years after graduation than on wages six years after graduation.
\end{abstract}

Richard J. Murnane

Graduate School of Education

Harvard University

13 Appian Way

Cambridge, MA 02138

and NBER

Frank Levy

Department of Urban Studies \& Planning

Massachusetts Institute of Technology

50 Memorial Drive

Cambridge, MA 02139
John B. Willett

Graduate School of Education Harvard University

13 Appian Way

Cambridge, MA 02138 
I. Introduction

The past decade has witnessed a growing popular literature on the transformation of U.S. industry. According to this literature, competitive pressures are forcing rapid restructuring in manufacturing firms and, more recently, in service firms as well. The result is a rapid upgrading in occupational skill requirements that has important implications for the nation's schools (e.g., Marshall and Tucker, 1992). While this hypothesis has received enormous attention, there is surprisingly little empirical research on the skills that occupations now require.

The strongest evidence supporting the increased demand for skilled workers is the sharp rise since the late 1970 s in the premium for increased schooling (Blackburn, Bloom, and Freeman, 1990; Katz and Murphy, 1992). A different kind of evidence is the twenty-year increase in wage dispersion among workers of a given age, education, gender, and race (Katz and Murphy, 1992). Some analysts have argued that this increase in within-group wage inequality reflects a rising price of dimensions of skill unobserved in the Current Population Survey data (Juhn, Murphy, and Pierce, 1989). To date, however, quantitative research has provided few clues about what skills might be in growing demand, ${ }^{1}$ and the growth in within-group wage dispersion can be explained in many other ways (Levy and Murnane, 1992).

The evidence from case studies is equally ambiguous. Here, 
discussions of rising skill requirements usually involve "best practice firms." Employees in such firms rotate through a number of different jobs, and are expected to exercise quality control, and suggest ways to solve problems and improve the production process. It is plausible that these employees exercise greater skill than employees in firms organized along Taylorist principles. ${ }^{2}$ But estimates of the percentage of employers that have restructured work to take better advantage of employees' skills range from numbers too small to affect economywide wage patterns to numbers large enough to influence these patterns. ${ }^{3}$

In this paper, we report on a study that examines whether basic cognitive skills (as distinct from formal schooling) are becoming more important in wage determination on an economy-wide basis. We focus on a central question: how the mathematics skills of graduating high school seniors affect their wages at age $24 .^{4}$ We ask this question first for students who graduated from high school in 1972, and again for students who graduated from high school in 1980. By examining how the mathematics score-wage relationship differs between the two cohorts, we can address two questions:

- Are basic cognitive skills becoming more important in determining wages on an economy-wide basis?

- How much of the increase in the college-high school wage premium during the 1980s stems from a widening of the skill gap between college graduates and high school graduates who 
did not go to college?

II. Data

We analyze data from two nationally representative databases that contain information on the labor market performance of students who graduated from high school in one of the last two decades. The National Longitudinal Study of the High School Class of 1972 (NLS72) provides information on the labor market experiences of 22,652 students who were first surveyed in 1972, when they were seniors in high school. High School and Beyond (HS\&B) provides information on the labor market experiences of 11,500 students first surveyed as high school seniors in 1980. Our analyses are based on men and women in the two data sets who had completed their formal education and were working for pay six years after graduating from high school.

Table 1 provides estimates of the sample means and standard deviations of the logarithm of hourly wages (in 1988 dollars) for males and females in the two data sets, grouped by highest educational attainment. To facilitate comparisons, the table also includes analogous data from March CPS surveys on the wages earned by 23- and 24-year old males and females in 1978 and 1986. The average values of the log wage differ somewhat between our analysis samples and the CPS samples, in part because the wage questions in the surveys differ, but the wage patterns in our analysis samples generally reflect the now familiar patterns in CPS-based studies of earnings inequality. 
For 24-year-old males whose highest educational attainment is high school graduation, the average wage was 16.5 percent lower in 1986 than in $1978 .^{5}$ For 24-year-old male college graduates, the average wage was only one percent lower in 1986 than in 1978. This pattern is consistent with CPS-based analyses showing that the college-high school wage gap for males widened during the 1980s, and that the increase stemmed primarily from the large decline in the real wages of male high school graduates (Levy and Murnane, 1992).

For 24-year-old females whose highest educational attainment is high school graduation, the average wage was four percent lower in 1986 than in 1978. For 24-year-old female college graduates, the average wage was one percent higher in 1986 than in 1978. This also fits the general pattern in CPS-based analyses, which show that women who did not go to college experienced less of a real wage decline than comparably educated men during the 1980s, but their wages lost ground relative to those of college-educated women. ${ }^{6}$

Table 1 also displays the estimated standard deviations of the logarithm of wages for 24-year-old males and females in each data set, arrayed by highest educational attainment. For seniors who did not go past high school, the pattern follows that present in CPS data: within-group wage variance is larger in 1986 than in 1978. For both male and female college graduates in our analysis samples, there is little difference between the 
variation in wages six years after high school graduation for 1980 graduates and 1972 graduates. This is one respect in which our analysis samples differ from the CPS. While we have no explanation for this difference, we note that other researchers have reported differences between CPS samples and other nationally representative data sets in the distribution of wages (cf. Gottschalk and Moffitt, 1992).

With the single exception described above, the wage trends in the NLS72 and HS\&B data sets follow closely the patterns present in CPS data. This suggests that relationships between measures of cognitive skills and wages in the NLS72 and HS\&B data sets may help to explain patterns in CPS data that cannot be explored because the latter data lack direct measures of cognitive skills.

In their last year in high school, participants in the NLS72 and HS\&B samples were administered tests of mathematics, reading, and vocabulary skills. Student responses on these tests were scaled by the Educational Testing Service using a 3-parameter Item-Response Theory (IRT) model to ensure that scores were equatable across data sets, within test. We chose the IRT-scaled mathematics score as our measure of cognitive skills because the results were consistently stronger than those using the other test scores.

The mathematics test assessed students' skill in following directions, working with fractions and decimals, and interpreting line graphs. (Appendix B lists four of the items from the 25 
item test.) The test contained no items requiring knowledge of geometry or advanced algebra. Thus, the test measured mastery of elementary mathematical concepts, not knowledge of more advanced mathematics.

The average test scores for males and females grouped by educational attainment are displayed in Table 2 and show several interesting patterns. Score on the math test is a strong predictor of subsequent educational attainment. For both males and females in the two data sets, the average math score for those who went on to graduate from college is almost twice that of those whose highest educational attainment was graduation from high school.

For both males and females, the average math score for the 1980 high school graduation cohort is lower than that for the 1972 cohort. This test score decline is frequently cited in critiques of U.S. schools, but the decline's sources are not well understood. Contributing factors appear to include a decline over the 1970s in the proportion of students taking the academic curriculum as opposed to the general or vocational curriculum, a drop in the frequency with which students take traditional college preparation core courses, and a decrease in the amount of time spent doing homework. ${ }^{\mathrm{s}}$

Finally, the decline over the 1970 s in high school seniors' mathematics scores is concentrated among those who did not go on to graduate from college. Among females whose highest 
educational attainment was high school graduation, the average mathematics score for those graduating in 1980 is .89 points lower than the average score for those graduating in 1972. Among females who went on to graduate from college, the comparable difference is only two-thirds as large. For males, the pattern is even more striking. The average math score for 1980 male high school seniors who subsequently graduated from college is higher than the average score for the comparable group of 1972 male high school graduates. This pattern raises the possibility that a widening of the college-high school skill differential contributed to the widening of the college-high school wage gap during the 1980s. We address this question in section IV.

\section{Analyses}

We replicated all of our analyses in four subsamples, treating men and women separately in the NLS72 and HS\&B data sets. For each subsample, we possessed cross-sectional information on the demographic characteristics and skill levels as of 12 th grade for each respondent, and longitudinal information on their post-high school educational attainment and work experience. We chose the natural logarithm of hourly wage six years after high school graduation (subsequently referred to as wage at age 24) because this is the only wage measure available for most participants in the HS\&B survey."

We were primarily interested in the impact of the direct measure of skill (the IRT-scaled mathematics score) on subsequent 
wages. We estimated this impact in the context of a model (Model b) that controlled for years of completed schooling, as well as for race and ethnicity, for whether the respondent attended high school in the South, for amounts of full-time and part-time labor force experience in the first six years after high school graduation, and for whether the dependent variable measured the wage in a full-time or part-time job. ${ }^{10}$ we also controlled for aspects of each respondent's family background, including the number of siblings, whether the family was headed by a single parent, and the highest grade completed of each parent. ${ }^{11}$

The regression coefficient associated with the direct skill measure provides an estimate of the impact of cognitive skills in explaining the variation in log wages among individuals with the same educational credentials and amount of labor force experience. For purposes of comparison, we also report the estimated coefficients of a conventional earnings model (Model a) that controls for years of completed schooling and family background variables, but does not include the mathematics score. We considered the mathematics score and the number of years of completed schooling to be measured with error. As is well known, measurement error in an explanatory variable tends to produce negative bias in the oLs parameter estimate associated with it, and due to predictor-predictor correlation, either a positive or negative bias in parameters associated with other predictors. For this reason, all regression models were fitted using the maximum likelihood methods of Fuller (1987) to correct 
our parameter estimates and goodness-of-fit statistics for the fallibility of these predictors. Conceptually, the Fuller correction procedure uses an estimate of a predictor's reliability to disattenuate the observed variance of the fallible predictor by removing measurement error variance from the appropriate diagonal element of the predictor-predictor covariance matrix prior to parameter estimation. The method has been well described in the literature, and has been implemented in commercially-available computer software (Fuller, 1988).

We obtained an estimate of the reliability of the mathematics score for each sample from an Educational Testing Service publication. ${ }^{12}$ For the male and female NLS72 samples, we estimated the reliability of the self-reported number of years of completed schooling using a method described in Kane \& Rouse (1993). The estimated reliabilities for the schooling measure (.89 for men, .92 for women) are close to the value of .915 used by Bishop (1989b). We assumed that the reliabilities estimated from the NLS72 samples also pertained to the self-reported number of years of schooling for our HS\&B samples. ${ }^{13}$

The sampling designs for both the NLS72 and HS\&B data sets result in over-representation of Black and Hispanic youth. To preserve the homoscedastic property of the error terms, we weighted all observations equally in fitting our models. However, we did test whether interactions between race/ethnicity and the measures of educational attainment and skill were predictors of the dependent variable and found that they were 
not. ${ }^{14}$ To illustrate the extent to which the sampling design influences the distribution of the variables used in the regressions, Appendix A presents sample means and (for nondichotomous variables) standard deviations for all variables used in the analysis, calculated both using the sampling weights, and weighting each observation equally.

IV. Results

Table 3 presents estimated regression coefficients and associated t-statistics for the fitted models in the two subsamples of males. Table 4 presents comparable estimates for the two subsamples of females.

\section{Family Background and Control Variables}

The regression coefficients associated with the family background predictors confirm patterns described in other research, although some of the estimates indicate weaker relationships than those found in studies providing more detailed measures of family background. For example, family structure is not a statistically significant predictor of log-wages in our samples. However, our measure of family structure represents whether a student lived in a single parent family as an adolescent, rather than the length of time spent in a singleparent family. Number of siblings is negatively related to subsequent wages, with the relationship stronger for males than females. Mother's and father's educational attainments are 
positively related to subsequent wages for females, but not for males. ${ }^{15}$

Controlling for family background and number of years of completed schooling (Model a), Black males graduating from high school in 1972 had wages at age 24 that were approximately six percent lower than those of white males. ${ }^{16}$ Among 1980 high school graduates with the same educational attainment, the comparable wage differential was 11 percent. Similar increases in the Black-White wage gap for males during the 1980 s are reported in studies based on the CPS (e.g., Bound and Freeman, 1992).

We do not find comparable wage gaps between Black and White females with the same educational attainment, or between Hispanics and Whites of either gender. In fact, controlling for educational attainment, Hispanic women graduating from high school in 1980 had a higher average wage at age 24 than their White female counterparts.

\section{Educational Attainment}

The estimated effects of educational attainment (years of completed schooling) on subsequent wages, as displayed in columns 1 and 3 of Tables 3 and 4, follow patterns that have become well known in recent years: the wage premium associated with postsecondary schooling was modest in the late 1970s, especially for men, but grew rapidly during the 1980s (cf. Blackburn, Bloom, \& Freeman, 1990; Katz \& Murphy, 1992). 
Our estimate is that, among males graduating from high school in 1972, each year of completed college was associated with a wage premium in 1978 (at age 24) of 2.2 percent above the wage earned by high school graduates with no postsecondary education. For males graduating from high school in 1980 the corresponding wage premium in 1986 is 4.5 percent. The analogous wage premiums for 24-year-old women are 5.5 percent in 1978 and 6.7 percent in $1986 .{ }^{17}$ Estimates of the college-high school wage differential computed from our results are lower than the premiums of 35-45 percent reported in other studies (cf. Levy and Murnane, 1992). The reason is that the college graduates in our data sets had less than two years to complete on-the-job training and to move through the relatively steep experience-earnings profile that highly educated workers tend to experience. ${ }^{18}$

The coefficient on years of schooling in Model a is a biased estimate of the wage increase at age 24 that an individual could expect from going to college because it does not take into account that high school graduates who go to college are more academically able, on average, than those who do not. The magnitude of the bias can be estimated by comparing the size of the coefficient on educational attainment in model a with that in model $b$, which contains the math score. Adding the math score to the model results in a decline of 41 percent in the coefficient on educational attainment for 1972 male high school graduates and a 52 percent decline for 1980 male high school graduates. The comparable figures for female graduates are 31 percent and 43 
percent.

A striking aspect of our findings is that including the math score in the model completely eliminates the increase between 1978 and 1986 in the wage premium from college attendance for females and reduces its magnitude for males from 100 percent to 62 percent. In other words, for females, all of the increase in the return to college attendance is explained by the increase in the return to cognitive skills. It is to this increase that we now turn.

Mastery of Basic Cognitive Skills and Wage Determination The test score measuring mastery of basic mathematics is more important in predicting subsequent wages among 1980 high school graduates with the same educational attainment than among 1972 graduates with the same attainment. The evidence comes from comparing the sizes of the coefficients on the mathematics score for the models displayed in columns 2 and 4 of Tables 3 and 4 . For males, the coefficient on the mathematics score for the cohort graduating from high school in 1980 (.011) is almost three times as large as the comparable coefficient for the cohort graduating in $1972(.004)$. For females, the coefficient on the math score for the later cohort $(.017)$ is almost twice as large as the comparable coefficient for the earlier cohort (.009). ${ }^{19}$

To provide a sense of the impact on wages of differences in math scores, we used the coefficients in Model b for each sample to predict wages at age 24 (in 1988 dollars) for high school graduates with no postsecondary education who differed in their 
scores on the mathematics test. In each case we set the family background characteristics to the average values in each sample. Figure 1 pertains to males; Figure 2 to females. The end points of the line segments in each figure represent the predicted wage associated with a mathematics score 6.25 points (the arithmetic average of the standard deviations of the math score in the four samples) above the mean or 6.25 points below the mean. ${ }^{20}$ In each figure the steeper slope of the line segment pertaining to 1980 high school graduates illustrates the central message of our paper: basic cognitive skills were more important determinants of wage at age 24 for 1980 high school graduates than for 1972 graduates.

For males graduating from high school in 1972, a 6.25 point difference in the mathematics score is associated with a predicted wage differential six years later of $\$ 0.24$ per hour (in 1988 \$), a very modest impact. For males graduating in 1980, the same test score differential is associated with a larger wage differential six years later, $\$ 0.57$ per hour. The same pattern is present for females, with the 6.25 point test score differential corresponding to a predicted wage differential of $\$ 0.39$ per hour for 1972 high school graduates and $\$ 0.74$ per hour for 1980 graduates. ${ }^{21}$

How important is the increase in the role of basic cognitive skills in determining wages? The question matters politically because it bears on the debate about the relative importance of changes in schools and changes in firms in restoring real wages 
to their earlier levels. As illustrated in Figure 1, males who graduated from high school in 1980 with strong basic math skills (6.25 points or approximately one standard deviation above the mean) have a lower predicted real hourly wage at age 24 (\$8.49) than that (\$9.25) of 1972 high school graduates with weak math skills ( 6.25 points below the mean). Thus, helping a male graduating from high school in 1980 to improve his math skills would contribute only modestly to the goal of increasing his wage level at age 24 to the level enjoyed by males graduating eight years earlier. It is possible that other skills students learn in school or at home have grown in importance in the labor market more than have basic math skills, but such skills have not yet been identified.

At the same time, Figure 1 also illustrates that 1980 high school seniors who lack basic math skills are at a greater disadvantage in the labor market relative to their peers than was the case for 1972 seniors weak in basic math. In fact, the predicted hourly wage $(\$ 7.40)$ for males entering the labor market directly after graduating from high school in 1980 with weak math skills corresponds to annual year-round full-time (1750 hours) earnings of $\$ 12,950$, which is just above the 1988 poverty line for a family of three. ${ }^{22}$ As a comparison of Figure 1 and Figure 2 illustrates, basic mathematical skills are more important predictors of wages at age 24 for 1980 female high school graduates than for male graduates. Thus, helping all students to acquire mastery of basic cognitive skills is an important 
national goal.

Sensitivity of Results to Model Specification

While we believe that the coefficients on the math score reported in the previous section represent our best estimates, there are other plausible specifications of Model b. The first three sections of Table 5 list coefficients on the math score and the number of years of completed schooling obtained by estimating Model $b$ with alternative values for the reliability of these key predictors. Section 1 repeats the estimates from Tables 3 and $4 .^{23}$ Section 2 presents estimates of the critical coefficients under the assumption that the reliability of the math score for each sample is five percentage points higher than the reliability reported in Rock (1985b). The logic for exploring the higher reliabilities is that the test scores for which reliability estimates are available (the formula scores) are not perfect linear transformations of the IRT scores used in our analyses. It is possible that the reliabilities of the IRT scores are slightly higher than those of the formula scores. To facilitate comparisons with studies that assume that all predictors are measured without error, section 3 of Table 5 presents coefficients estimated under the assumption of perfect reliability for the math score and years of completed schooling for all four samples.

As expected, increasing the assumed value of the reliability 
of the math score reduces somewhat the size of the coefficient associated with this variable. However, the basic message of the paper, that the relationship between the math score and subsequent wages is stronger for 1980 high school graduates than for 1972 graduates, remains.

One other specification issue involves a potential interaction between the mathematics score and years of completed schooling. Blackburn \& Neumark (1993) report that cognitive skills have a larger impact on subsequent earnings for males who complete college than for males who enter the workforce directly after high school graduation. We estimated models that included a two-way interaction between the mathematics score and the number of years of completed schooling under the assumption that both variables and their interaction are measured with error.

Consistent with Blackburn \& Neumark, we find for men a positive interaction between skills and educational attainment in HS\&B (i.e., the 1980s). The interaction is not present for men in NLS72 (the 1970s). By themselves, these results suggest that the economy changed in ways that made cognitive skills particularly important for college graduates. This conclusion is called into question, however, by the pattern for women: a positive interaction between skills and educational attainment in the 1970s, but no such interaction in the 1980s. There are a number of potential explanations for these opposing results. But the basic message is that the skills-education interaction must be interpreted with caution. ${ }^{24}$ 
To examine whether the fitted models that included the interaction term show a growing role for skills in predicting wages, we used these coefficients to estimate the impact of a one point difference in math score on the natural logarithm of wage for high school graduates who did not go to college (years of completed schooling $=12$ ). The estimates are presented in the last section of Table 5. The predicted impacts of skill differences on log wages calculated from the model with the skill-schooling interaction are smaller than the predicted impacts from the main effects model, especially for men. However, the estimates support the theme of the paper: skills are stronger determinants of subsequent wages for 1980 high school graduates than for 1972 graduates.

Changing Occupational Content or Occupational Shifts

One potential explanation for the increase in the importance of skills in determining wages is a decline between 1978 and 1986 in the percentage of young workers employed in occupations, such as machine operators, that paid relatively high wages but did not require mastery of basic math skills. To investigate the importance of such compositional effects, we re-estimated Model b for each of our four samples, including a series of dummy variables for two-digit occupations. For males, inclusion of 10 occupational indicators reduced the coefficient on the math score by less than 10 percent for both the 1978 and the 1986 samples of 24-year-olds, and the estimated impact of the math score on wages in 1986 remained more than twice as large as the impact on wages 
in 1978. For women, inclusion of the occupational indicators reduced the coefficient on the mathematics score by less than 20 percent in the two samples, and the coefficient pattern was not affected. This suggests that the increase in the importance of cognitive skills in wage determination primarily reflects increases in the demand for skills within occupational groups rather than compositional effects.

Growing Skill Gaps as an Explanation for Growing Wage Gaps

As shown in Table 2 , the average math score differential between high school seniors who subsequently graduated from college and those who did not go to college was larger for the 1980 high school graduation cohort than for the 1972 cohort - a supply side phenomenon. In sections II and III, we noted that this increase in the college-high school skill gap could contribute to the increase in the college-high school wage gap. To test the quantitative importance of this supply side change, we estimated the college-high school skill differential in each sample, net of family background effects, and used the results to calculate the predicted increase between 1972 and 1980 in the college-high school skills differential. For males, the increase was 1.15 points; for females, 0.28 points. Then, for each gender, we multiplied the increase in the skill differential by the estimated total impact of a one point difference in a 1980 high school senior's math score on the natural logarithm of wages six years later (.013 for males, and .022 for females). ${ }^{25}$ The predicted increase in the college-high school wage gap stemming 
from the increase in the college-high school skills gap is .015 for males and .006 for females, both of which are less than 18 percent of the increase in the college-high school wage differentials reported above (.088 for men, .044 for women).$^{26}$ These results support Katz and Murphy's (1992) conclusion that most of the increase in the college-high school wage differential stemmed from an increase in the demand for skills.

Skills, Wage Determination, and the Incentives to Learn

At first glance, the growing importance of skills in wage determination should increase the incentive for high school students to take the demanding courses that increase cognitive skills. A counter-argument comes from the work of Bishop (1989a) and Rosenbaum and Kariya (1991) who argue that there is too little contact between U.S. employers and U.S. high schools. As a result, employers who hire high school graduates cannot judge their ability at entry and so student skills are not initially rewarded. ${ }^{27}$ To test this counter-argument in our data, we reestimated Model $b$ with the logarithm of wage two years after high school as the dependent variable. The estimated coefficients on math score for the different samples are displayed in row 3 of Table 6. To facilitate comparison, row 2 of Table 6 provides the analogous coefficients for identical subsamples, using the logarithm of wage six years after high school graduation as the dependent variable. ${ }^{28}$ All of the coefficients in Table 6 were estimated using samples of high school graduates who did not go to college. 
The results show that the timing of the wage measure matters. For males graduating from high school in either 1972 or 1980, the mathematics score is not positively related to wage two years later (row 3). It is, however, positively related to wage six years later, with the relationship stronger for 1980 graduates than for 1972 graduates. ${ }^{29}$ For females, high school math score is positively related to wage two years later and to wage six years later. Among females graduating from high school in 1980, the math score is a much stronger predictor of wage six years after high school graduation than of wage two years after graduation. ${ }^{30}$

V. Summary

On an economy-wide basis, basic cognitive skills were more important predictors of wage six years after high school in the mid-1980s than in the late 1970s. This phenomenon is rooted in demand shifts and reflects primarily changes within occupational groups. It applies to persons of all educational levels, showing that a rising demand for basic skills is part of the explanation for the 30 percent increase since 1970 in within-group wage variation. ${ }^{31}$ Our results indicate that the increased role of cognitive skills is not limited to a small set of best practice firms, but is general enough to appear clearly in national random samples.

We emphasize that our findings concern the demand for basic 
cognitive skills, including the ability to follow directions, manipulate fractions and decimals, and interpret line groups. The mathematics test contains no items requiring knowledge of geometry or advanced algebra. Thus a high school senior's mastery of skills taught in American schools no later than the eighth grade is an increasingly important determinant of subsequent wages. This finding is surprising until one notes that only about half of the nation's high school seniors have mastered computation with decimals, fractions, and percents, and recognize geometric figures (Mullis et al., 1991).

The restructuring literature usually ends in a call for better schooling. One would hope that the increased payoff to cognitive skills would lead to this call coming from students as well as policy experts. But as we have shown, the disjuncture between U.S. employers and U.S. schools undermines the incentive that might have arisen. The resulting market failure makes the necessary job of educational reform that much harder. 
Table 1: Sample means (and standard deviations) of the natural logarithm of hourly wage (in 1988 dollars) six years after high school graduation, by highest educational attainment (sample weights used in the estimations)."

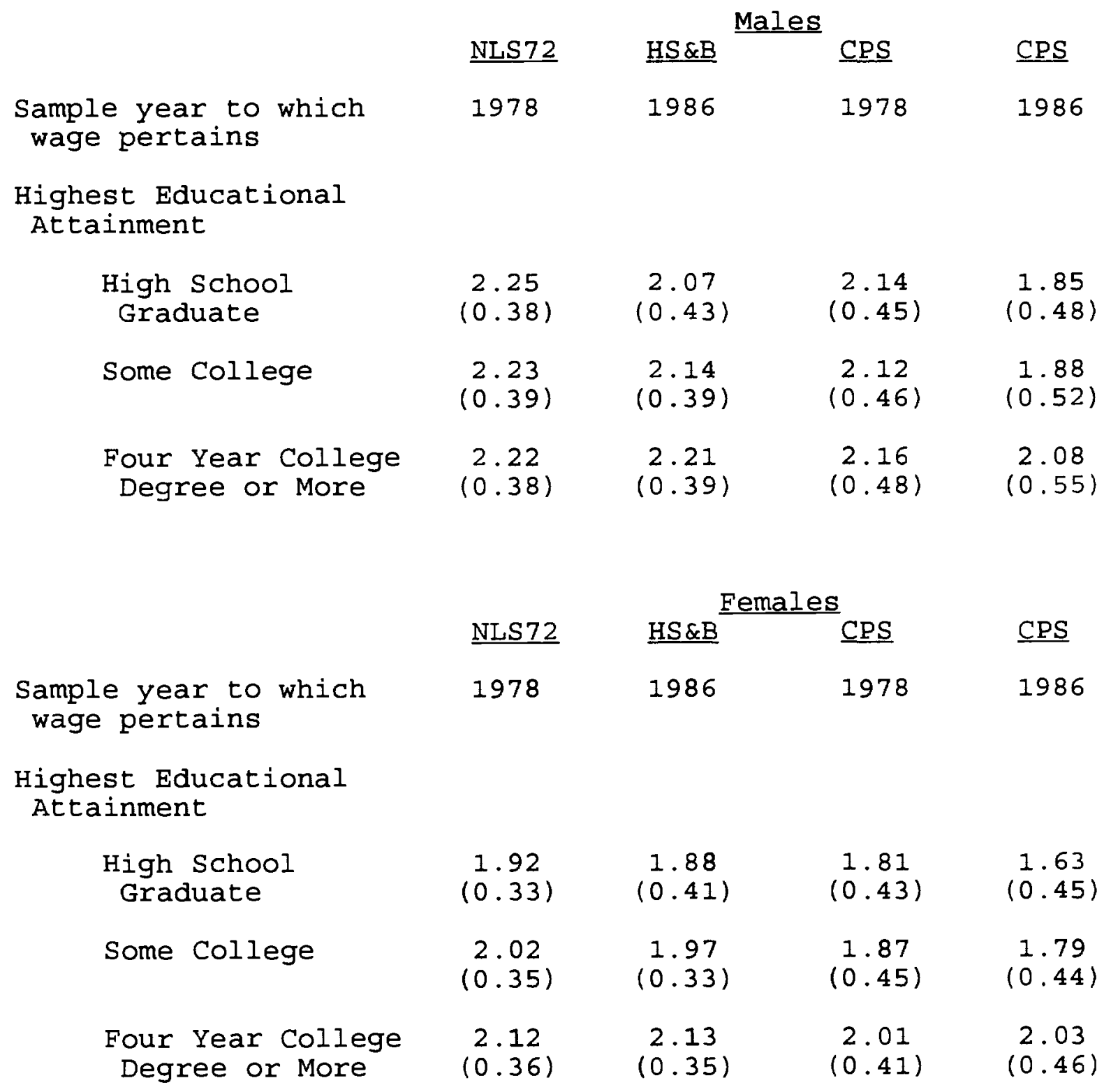

a Since the year of high school graduation is not known for individuals included in the CPS samples, the CPS samples were drawn to include all 23- and 24-year olds for whom a wage is recorded for the relevant year, 1978 or 1986. 
Table 2: Sample means (and standard deviations) of the IRTScaled Mathematics Test Score, by highest educational attainment (sample weights used in the estimations).

$\underline{\text { NLS72 }} \underline{\text { Males }} \underline{\text { HS\&B }} \quad \underline{\text { NLS72 }} \frac{\text { Females }}{\text { HS\&B }}$

Highest Educational

Attainment

$\begin{array}{lllll}\begin{array}{l}\text { High School } \\ \text { Graduate }\end{array} & 10.48 & 9.87 & 9.82 & 8.93 \\ \text { Some College } & (6.45) & (6.58) & (6.31) & (5.75) \\ & 15.21 & 14.84 & 13.80 & 12.90 \\ & (6.42) & (6.10) & (6.63) & (5.58) \\ \text { Four Year College } & 18.94 & 19.67 & 17.79 & 17.19 \\ \text { Degree or More } & (5.39) & (4.89) & (5.52) & (5.44) \\ & & & & \\ \text { Sample } & 13.94 & 13.28 & 13.09 & 12.10 \\ & (7.12) & (7.21) & (7.02) & (6.46)\end{array}$


Table 3. Estimated coefficients (and t statistics) from models relating skill measures to the log of hourly wage six years after high school graduation, for males.

$\underline{\mathrm{NLS} 72}$

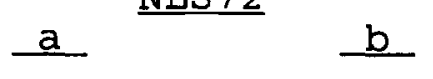

$\underline{\mathrm{HSB}}$

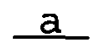

Education:

Years of Completed Schooling

Mathematics Score

Family Background:

Single

Parent

Household

Number of

Siblings

Mother's Highest

Grade Completed

Father's Highest

Grade Completed

Controls:

went to High School in South

Black

Hispanic

Years Full-Time Work Experience

Years Part-Time Work Experience

Wage is for PartTime Work

Intercept

$R^{2}$

Number of Observations
.022
(3.63)
.013
$(1.85)$
- $\quad .004$
(3.13)

.044

(5.72)

$---$

(2. 22)

.011

(5.06)

$\begin{array}{rrrr}-.018 & -.017 & -.030 & -.031 \\ (-.913) & (-.882) & (-1.19) & (-1.25) \\ -.006 & -.006 & -.011 & -.010 \\ (-1.95) & (-1.97) & (-1.97) & (-1.84) \\ -.006 & -.007 & .006 & .004 \\ (-1.62) & (-1.81) & (1.10) & (.777) \\ .002 & .001 & -.008 & -.007 \\ (.572) & (.288) & (-1.50) & (-1.43)\end{array}$

-.071
$(-5.49)$

$-.071$

$-.045$

$(-2.22)$

$-.028$

$(-5.44)$

$(-1.38)$

$-.066$

$-.042$

$-.116$

$(-4.48)$

$-.056$

$(-2.97)$

$(-1.78)$

$(-1.98)$

$-.048$

$-.031$

$(-1.02)$

.015

(.640)

.062

(2.46)

.045

.043

(7.68)

.022

(2.89)

.020

(2.63)

$-.001$

$-.002$

(-.218)

.017

(1.55)

.015

(1.37)

$-.067$

$-.066$

$-.032$

$-.032$

$(-.572)$

$(-.576)$

1.92

2.01

1.52

1.69
.041
.061
.078
.038

4114

1980

1980 
Table 4. Estimated coefficients (and t statistics) from models relating skill measures to the log of hourly wage six years after high school graduation, for females.

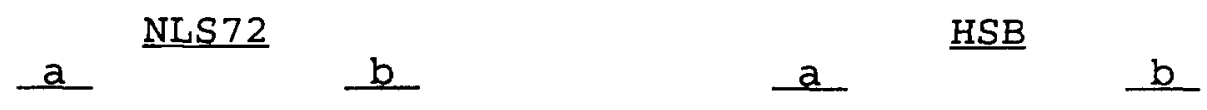

Education:

Years of Completed Schooling

.054

(11.07)

.037

(6.74)

-. $\quad .009$

(7.18)

score

Family Background:

Single

Parent

Household

Number of

Siblings

Mother's Highest

Grade Completed

Father's Highest

Grade Completed

Controls:

Went to High School in South

Black

Hispanic

Years Full-Time

Work Experience

Years Part-Time

Work Experience

Wage is for Part-

Time Work

Intercept

$\mathrm{R}^{2}$

Number of

Observations
$-.017$

$(-1.07)$

$-.002$

$(-.792)$

$-.002$

$(-.744)$

.008

(2.47)

.007

(2.40)

.006

(1.86)

.005

(1.88)

$-.041$

$(-3.47)$

$-.039$

$(-3.30)$

.002

$(.086)$

.052

(2.67)

.008

(.291)

.045

(1.57)

.026

(5.25)

.023

(4.57)

$-.003$

$(-.360)$

$-.005$

$(-.579)$

$-.041$

$-.045$

$(-2.26)$

$(-2.49)$

1.05

1.21

.078

.094

3925
.014

(.640)

.004

(.198)

(10.63)

(5.32)

.017

(8.57)
$-.007$

(-1.55)

.014

(2.97)

.003

(.697)
$-.077$

$(-4.57)$

$(-5.51)$

$-.025$

$(-1.15)$

(2. 42$)$

.047

(2.26)

.105

(4.91)

.049

(7.44)

.022

(2.66)

.010

(.288)

.720

.131

.171
.940

(6.57)

(1.60)

.030

$(.870)$ 
Table 5: Coefficients on mathematics score and years of completed schooling from versions of Model $B$ with different predictor reliability specifications.

$\underline{\text { Sample }}$

\section{Estimated Coefficients}

$\begin{array}{llll}\text { Math } & \text { Years of } & \text { Math } & \text { Years of } \\ \text { Score } & \text { Completed } & \text { Score } & \text { Completed } \\ & \text { Schooling } & & \text { Schooling }\end{array}$

.89

.89

.92

.92

HS \&B Females $\quad .83$

2.NLS72 Males $\quad .92$

HS\&B Males .91

NLS72 Females .90

HS \&B Females .88

3.NLS72 Males 1.0

HS\&B Males 1.0

NLS72 Females 1.0

HS\&B Females 1.0

4.NLS72 Males $\quad .87$

HS\&B Males $\quad .86$

NLS72 Females .85

HS\&B Females .83
.89

.89

.92

.92

1.0

1.0

1.0

1.0

.89

.89

.92

.92

$$
\begin{array}{ll}
.0041 \star & .0131 \star \\
.0110^{\star} & .0205^{\star} \\
.0089 \star & .0372^{\star} \\
.0173^{\star} & .0370^{\star}
\end{array}
$$

$.0038 * \quad .0139 *$

$.0098 * \quad .0230 *$

$.0081 * \quad .0388 *$

$.0156 * \quad .0398 *$

$.0035 * \quad .0114 *$

$.0087 * \quad .0214 *$

$.0131 * \quad .0388 *$
$.0073 * \quad .0346 *$
Two-Way

Interaction of Score* and

5. Predicted impact on Ln (wage) of a one point difference in IRT Math score for a high school graduate who did not go to college, calculated from coefficients in model including the two-way math score by schooling interaction
NLS72 Males
HS\&B Males
NLS72 Females
HS\&B Females

.0025

.0066

.0070

.0192

*Significant at the .05 level in a two-tailed test 
Table 6: Estimated regression coefficients, t-statistics, and sample size associated with the prediction of the log of hourly wage by IRT-scaled mathematics score (controlling for family background, race, ethnicity, and work experience) in several subsamples of high school graduates who did not go to college.

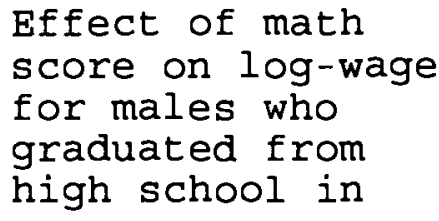

graduated from

Dependent

Subsample

All respondents Log-wage 6

with a wage value years after

in the 6th year high school

after high school graduation

graduation

\begin{abstract}
All respondents with a wage value in both the 2 nd and 6 th year after high school graduation
\end{abstract}
All respondents with a wage value in both the 2 nd and 6 th year after high school
graduation Log-wage 6 years after high school graduation

.003

(1.25)

$\mathrm{N}=1192$

1972

1980

(2.18)

$\mathrm{N}=1989$
(2.37)
$\mathrm{N}=923$

.007

Log-wage

2 years after high school graduation

\begin{abstract}
Effect of math score on log-wage for females who graduated from high school in
\end{abstract}


Appendix A. Weighted and unweighted means and standard deviations* for variables used in regressions.

\begin{tabular}{|c|c|c|c|c|c|c|c|c|}
\hline & & & es & & & Fem & es & \\
\hline & NL & & $\underline{\mathrm{HS}}$ & & $\underline{\mathrm{NL}}$ & & $\underline{\mathrm{HS}}$ & \\
\hline & wtd. & $\begin{array}{l}\text { un- } \\
\text { wtd. }\end{array}$ & wtd. & $\begin{array}{l}\text { un- } \\
\text { wtd. }\end{array}$ & wtd. & $\begin{array}{l}\text { un- } \\
\text { wtd. }\end{array}$ & wtd. & $\begin{array}{l}\text { un- } \\
\text { wtd. }\end{array}$ \\
\hline $\begin{array}{l}\text { og of wage } \\
\text { Six Years }\end{array}$ & $\begin{array}{c}2.24 \\
(0.38)\end{array}$ & $\begin{array}{c}2.23 \\
(0.39)\end{array}$ & $\begin{array}{c}2.12 \\
(0.41)\end{array}$ & $\begin{array}{c}2.10 \\
(0.42)\end{array}$ & $\begin{array}{c}2.00 \\
(0.35)\end{array}$ & $\begin{array}{l}1.99 \\
(0.35)\end{array}$ & $\begin{array}{c}1.97 \\
(0.38)\end{array}$ & $\begin{array}{c}1.96 \\
(0.39)\end{array}$ \\
\hline
\end{tabular}

After High

School Grad.

Number of Years

$\begin{array}{llllllll}\text { of Completed } 13.45 & 13.37 & 13.53 & 13.56 & 13.50 & 13.43 & 13.71 & 13.75\end{array}$

$\begin{array}{lllllllll}\text { Schooling } & (1.72) & (1.70) & (1.75) & (1.73) & (1.73) & (1.72) & (1.78) & (1.74)\end{array}$

$\begin{array}{lllllllll}\text { Mathematics } & 13.94 & 13.32 & 13.28 & 12.06 & 13.09 & 12.47 & 12.10 & 11.18\end{array}$

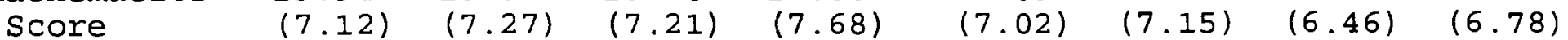

Family Background:

\begin{tabular}{|c|c|c|c|c|c|c|c|c|}
\hline $\begin{array}{l}\text { Single Parent } \\
\text { Household }\end{array}$ & .19 & .20 & .17 & .22 & .20 & .22 & .17 & .23 \\
\hline $\begin{array}{l}\text { Number of } \\
\text { Siblings }\end{array}$ & $\begin{array}{c}3.04 \\
(2.14)\end{array}$ & $\begin{array}{c}3.16 \\
(2.21)\end{array}$ & $\begin{array}{c}2.99 \\
(1.67)\end{array}$ & $\begin{array}{c}3.17 \\
(1.76)\end{array}$ & $\begin{array}{c}3.09 \\
(2.11)\end{array}$ & $\begin{array}{c}3.19 \\
(2.21)\end{array}$ & $\begin{array}{c}2.85 \\
(1.67)\end{array}$ & $\begin{array}{c}3.09 \\
(1.76)\end{array}$ \\
\hline $\begin{array}{l}\text { Mother's } \\
\text { Highest } \\
\text { Grade } \\
\text { Completed }\end{array}$ & $\begin{array}{l}12.27 \\
(1.97)\end{array}$ & $\begin{array}{l}12.20 \\
(2.00)\end{array}$ & $\begin{array}{l}12.73 \\
(2.09)\end{array}$ & $\begin{array}{l}12.47 \\
(2.10)\end{array}$ & $\begin{array}{l}12.33 \\
(2.07)\end{array}$ & $\begin{array}{l}12.23 \\
(2.08)\end{array}$ & $\begin{array}{l}12.68 \\
(2.09)\end{array}$ & $\begin{array}{l}12.40 \\
(2.10)\end{array}$ \\
\hline $\begin{array}{c}\text { Father's } \\
\text { Highest } \\
\text { Grade }\end{array}$ & $\begin{array}{l}12.46 \\
(2.33)\end{array}$ & $\begin{array}{l}12.39 \\
(2.39)\end{array}$ & $\begin{array}{l}13.03 \\
(2.66)\end{array}$ & $\begin{array}{l}12.71 \\
(2.56)\end{array}$ & $\begin{array}{l}12.55 \\
(2.42)\end{array}$ & $\begin{array}{l}12.48 \\
(2.46)\end{array}$ & $\begin{array}{l}13.03 \\
(2.59)\end{array}$ & $\begin{array}{l}12.64 \\
(2.51)\end{array}$ \\
\hline
\end{tabular}

Completed

Controls:

$\begin{array}{lllllllll}\begin{array}{l}\text { Went to High } \\ \text { School in }\end{array} & .28 & .35 & .31 & .39 & .30 & .37 & .29 & .38\end{array}$

South

\begin{tabular}{|c|c|c|c|c|c|c|c|c|}
\hline Black & .06 & .10 & .09 & .22 & .09 & .13 & .09 & .22 \\
\hline Hispanic & .03 & .04 & .09 & .25 & .03 & .04 & .07 & 22 \\
\hline $\begin{array}{l}\text { Years Full- } \\
\text { Time Work } \\
\text { Experience }\end{array}$ & $\begin{array}{c}2.54 \\
(1.60)\end{array}$ & $\begin{array}{c}2.57 \\
(1.60)\end{array}$ & $\begin{array}{c}3.11 \\
(1.48)\end{array}$ & $\begin{array}{c}2.97 \\
(1.48)\end{array}$ & $\begin{array}{l}2.23 \\
(1.49)\end{array}$ & $\begin{array}{l}2.24 \\
(1.49)\end{array}$ & $\begin{array}{c}2.67 \\
(1.51)\end{array}$ & $\begin{array}{c}2.54 \\
(1.51)\end{array}$ \\
\hline $\begin{array}{l}\text { Years Part- } \\
\text { Time Work } \\
\text { Experience }\end{array}$ & $(0.32)$ & $(0.32)$ & $\begin{array}{l}.50 \\
(.98)\end{array}$ & $\begin{array}{c}.55 \\
(1.03)\end{array}$ & $\begin{array}{c}.47 \\
(0.69)\end{array}$ & $\begin{array}{c}.47 \\
(0.68)\end{array}$ & $\begin{array}{c}.87 \\
(1.19)\end{array}$ & $\begin{array}{c}.87 \\
(1.19)\end{array}$ \\
\hline $\begin{array}{l}\text { Wage is for } \\
\text { Part-Time work }\end{array}$ & .03 & .03 & .03 & .03 & .11 & .11 & .06 & .06 \\
\hline Number of & 4114 & 4114 & 1980 & 1980 & 3925 & 3925 & 2163 & 2163 \\
\hline
\end{tabular}

Observations

"Standard deviations are not reported for dichotomous variables 
Appendix B: Questions from Mathematic Exam Administered to Samples of American High School seniors in 1972 and 1980.

Directions: Each problem in this section consists of two quantities, one placed in Column A and one in Column B. You are to compare the two quantities and circle the letter
$A$ if the quantity in Column $A$ is greater;
$B$ if the quantity in Column B is greater;
$C$ if the two quantities are equal;
$D$ if the size relationship cannot be determined from the information given.

Column A

1 . Length represented by 3 inches on a scale of 4 feet to an inch
Column B
A length of
A $B \quad C \quad D$

12 feet

$$
\begin{aligned}
& \frac{1}{P}=\frac{4}{3} \\
& \frac{1}{Q}=\frac{3}{4}
\end{aligned}
$$

P

Q

A $B \quad C \quad D$

Cost per apple at a rate of 3 apples Cost per apple at
a rate of $\$ 2.00$ per dozen apples for $\$ 0.50$

$$
\begin{aligned}
& 2(10)^{3}+4(10)^{2} \text { A B C D } \\
& +5(10)
\end{aligned}
$$


Bishop, John H, "Incentives for Learning: Why American High School students Compare So Poorly to Their Counterparts Overseas," Working paper \#89-09, Cornell University, Ithaca, NY, (1989a).

Bishop, John H, "Is the Test Score Decline Responsible for the Productivity Growth Decline?" American Economic Review 79 (March 1989b) 1, $178-197$.

Blackburn, McKinley L., David E. Bloom, and Richard B. Freeman, "The Declining Economic Position of Less Skilled American Men," in Gary Burtless (ed.) A Future of Lousy Jobs? (Washington, D.C.: The Brookings Institution, 1990).

Blackburn, McKinley L., and David Neumark, "Omitted-Ability Bias and the Increase in the Return to Schooling," Journal of Labor Economics (1993, forthcoming).

Bound, John, and Richard B. Freeman, "What Went Wrong? The Erosion of Relative Earnings and Employment Among Young Black Men in the 1980s," The Quarterly Journal of Economics (February 1992), 201-232.

Bound, John, Zvi Griliches, and Bronwyn H. Hall, "Wages, Schooling and IQ of Brothers and Sisters: Do the Family Factors Differ?" International Economic Review 27 (February 1986)1, $77-105$. 
Cohen, Jacob, and Patricia Cohen, Applied Multiple Regression/ Correlation Analysis for the Behavioral Sciences (second edition) (Hillsdale, N.J.: Lawrence Erlbaum Associates, 1983).

DuMouchel, William H., and Greg J. Duncan, "Using Sample Survey Weights in Multiple Regression Analyses of Stratified Samples," Journal of the American Statistical Association 78 (September 1983), 535-543.

Fuller, w. A., EV Carp (Ames, Iowa: Iowa State Statistical Laboratory, 1988).

Fuller, W. A., Measurement Error Models (New York: John Wiley \& Sons, 1987).

Gottschalk, Peter, and Robert Moffitt, "Earnings and Wage Distributions in the NLS, CPS, and PSID," Part I of Final Report to the U.S. Department of Labor, Grant No. E-9-J-0047, "Earnings Mobility and Earnings Inequality in the United States," awarded to the National Bureau of Economic Research, (May 1992).

Johnston, William B. and Arnold E. Packer, Workforce 2000 , Work and Workers for the 21st Century (Washington D.C.: Hudson Institute, 1987).

Juhn, Chinhui, Kevin M. Murphy, and Brooks Pierce, "Wage Inequality and the Rise in Returns to Skill," Paper presented at the Universities Research Conference "Labor Markets in the 1990s," (November 13, 1989). 
Kane, Thomas J. and Cecilia E. Rouse, "Labor Market Returns to Two- and Four-Year College: Is a Credit A Credit and Do Degrees Matter?" Harvard University, Kennedy School of Government Faculty Research Working Paper Series, No. R-93-38, (December, 1993) .

Katz, Lawrence F. and Kevin M. Murphy, "Changes in Relative Wages, 1963-1987: Supply and Demand Factors," Quarterly Journal of Economics, 107 (February 1992), 35-78.

Koretz, Daniel M, Educational Achievement: Explanations and Implications (Washington, D.C.: Congressional Budget Office, 1987).

Krueger, Alan B, "How Computers Have Changed the Wage Structure: Evidence from Microdata, 1984-89," Quarterly Journal of Economics, 108 (February 1993)1, 33-60.

LevY, Frank and Richard J. Murnane, "U.S. Earnings Levels and Earnings Inequality: A Review of Recent Trends and Proposed Explanations," The Journal of Economic Literature, 30 (September 1992), 1332-1381.

Lillard, Lee A, "Inequality: Earnings vs. Human Wealth," American Economic Review, 67 (March 1977)2, $42-53$.

Lord, Fred M. and Melvin R. Novick, statistical Theories of Mental Test Scores (Reading, MA.: Addison-Wesley, 1968). Marshall, Ray and Marc Tucker, Thinking for a Living (New York: Basic Books, 1992). 
Mishel, Lawrence and Jared Bernstein, "Declining Wages for High School and College Graduates: Pay and Benefits Trends by Education, Gender, Occupation, and State, 1979-1991," Briefing paper, Washington, D.C.: Economic Policy Institute, (1992). Mullis, Ina V. S., John A. Dossey, Eugene H. Owen, and Gary W. Phillips, The State of Mathematics Achievement, Report Prepared by Educational Testing Service for National Center for Education Statistics, Washington, D.C., (June 1991).

Osterman, Paul, "How Common Is Workplace Transformation?" Industrial and Labor Relations Review 47 (January 1994)2, 173188.

Rivera-Batiz, Francisco L, "Quantitative Literacy and the Likelihood of Employment Among Young Adults," Journal of Human Resources 27 (Spring 1992) 2, 313-328.

Rock, Donald A. et al, Factors Associated with Decline of Test Scores of High School Seniors, 1972 to 1980: A Study of Excellence in High School Education: Educational Policies, School Quality, and student outcomes (Princeton, NJ: Educational Testing Service, December 1985a). Rock, Donald A. et al, psychometric Analysis of the NLS and the High School and Beyond Test Batteries: A Study of Excellence in High School Education: Educational Policies, School Quality, and Student outcomes (Princeton, NJ: Educational Testing Service, September 1985b). 
35

Rosenbaum, James E., and Takehiko Kariya, "Do School Achievements Affect the Early Jobs of High School Graduates in the United States and Japan?," Sociology of Education 64(April 1991), 78 95. 


\section{Endnotes}

1. Krueger (1993) reports a slight increase between 1984 and 1989 in the return to computer usage. Rivera-Batiz (1992) and Bishop (1989a,b) provide evidence about the importance of particular skills in explaining labor force outcomes at one point in time.

2. In explaining the sources of effective performance in best practice firms, analysts differ in their judgments about the relative importance of hiring workers with relatively high skill levels and investing in training to develop workers' skills on the job. Compare, for example, Brown, Reich, and Stern (1992) and Packer and Johnston (1987).

3. Marshall \& Tucker (1992, p.64) report an estimate of less than 5\%. Osterman (1994) reports an estimate of $35 \%$, based on a survey of private sector establishments with 50 or more employees he conducted in 1992 .

4. To be precise, wages are measured six years after high school graduation, a time when most, but not all, students are 23 or 24 years of age. For ease of exposition, we assume that all members of the four samples are aged 24 when their wages were measured. 5. Because of the nonlinear nature of the log transformation, we are referring to differences in the geometric mean, rather than the arithmetic mean. The 16.5\% decline in the geometric average wage of male high school graduates was calculated as $\left(e^{-.18}-1\right)$. 6. See, for example, Mishel and Bernstein (1992). 
7. As reported in Rock et al. (1985a, p. 13), 18 of the 25 items on the mathematics test were either identical (12) or had minor editorial or format changes (6) between the 1972 and 1980 test administrations. See Rock et al. (1985b) for a description of the application of item-response theory that produced fully equatable scores for the 1972 and 1980 high school seniors. We would like to thank Donald Rock of the Educational Testing Service for making the IRT-based test scores available to us.

In a subsequent endnote, we report the results of estimating models in which the vocabulary and reading scores were used as skill measures, both individually and along with the math score. 8. See Rock et al. (1985a) for a discussion of reasons for the test score decline. In a later publication, Koretz (1987) documented that the test score decline ended with the cohort of children born in 1962. The evidence for the cohort effect is that the approximate timing of the end of the decline was 1971 for 9-year-olds, 1975 for 13-year-olds, and 1979 for 17-yearolds.

9. The wage used in our analyses is the usual hourly wage in the primary job held at the time the survey was conducted or, for individuals not working at the time of the survey, the hourly wage on the most recently held job (so long as it was held within the previous year). The survey questions ask for the current salary (before deductions) and for the time period (e.g. hour, week, month, year) to which the salary pertains. We then calculated the hourly wage to be the salary divided by the usual 
number of hours in the pay period.

10. We defined a part-time job as one in which the respondent worked fewer than 30 hours per week. The number of years of full-time work experience since high school graduation was calculated by dividing by 12 the number of months between high school graduation and the date of the survey six years later in which an individual worked for at least 30 hours per week for at least one week. An analogous method was used in calculating the number of years of part-time experience. As indicated in Appendix $A$, the average values for these experience variables are quite low, especially since the variable includes work experience prior to post-secondary school completion. Part of the explanation is that many members of our samples had little recorded work experience while in college. Another part may be that some members of the sample did not answer correctly the complicated survey questions dealing with work experience. 11. We used the method described by Cohen \& Cohen (1983) to resolve the problem of missing values. Under this strategy, missing values for a particular variable are replaced by a constant arbitrary value and an additional dichotomous variable is included to distinguish, and hold separate, the replacement values.

12. As reported in Rock et al. (1985b), the estimated reliabilities of the formula score on the vocabulary, reading, and math tests are as follows: NLS72 males $(.78, .79, .87)$; NLS72 females $(.78, .79, .85)$; HS\&B males $(.83, .80, .86)$; HS\&B females 
$(.82, .78, .83)$. These were obtained using Cronbach's coefficient alpha (Lord \& Novick, 1968). We use IRT scores (as opposed to formula scores) in our analyses because the IRT scores are equatable across tests. In each of our four samples the correlation between the IRT score and the formula score was greater than .95. For this reason we took the advice of Donald Rock (of Educational Testing Service) and assumed that the reliabilities of the formula scores also pertained to the IRT scores. In section IV we examine the sensitivity of the results to the assumption that the reliabilities of the IRT scores are higher than those of the formula scores.

13. For each person in their NLS72 data set, Kane \& Rouse (1993) have two indicators $\left(S_{1}\right.$ and $\left.S_{2}\right)$ of the true number of years of completed schooling $(S)$. The first $\left(S_{1}\right)$ is a self-reported measure, which we also use in our research; the second $\left(S_{2}\right)$ is a measure constructed from college transcripts. We are indebted to Tom Kane for providing us with the latter measure. Assuming that the measurement errors in the two indicators of schooling ( $\epsilon_{1}$ and $\epsilon_{2}$ ) are independent and that both are independent of $S$, the variance in true schooling $\left(\sigma_{s}{ }^{2}\right)$ is estimated by the covariance of $S_{1}$ and $S_{2}$. The reliability of the self-reported measure of schooling is the ratio of the estimates of $\sigma_{s}{ }^{2}$ and $\sigma_{s_{1}}{ }^{2}$. 14. See DuMouchel and Duncan (1983) for a discussion of the merits of weighting observations equally and weighting observations by the sample weights in fitting regressions to stratified samples. 
15. Both males and females who went to high school in the South had lower subsequent wages than students who lived in other parts of the country. However, since we lack an indicator of the region in which an individual worked when the wage level was measured at age 24 , we do not know whether this reflects regional wage patterns or differences in school quality not reflected in the skills measure.

The coefficients on the variables measuring years of fulltime and part-time work experience are unstable because they are highly collinear with highest educational attainment.

16. Throughout the paper, the percentage wage differential associated with a one unit difference in the value of an explanatory variable with a coefficient, $b$, is computed by the formula: $e^{b}-1$.

17. When Model a is estimated without controlling for full-time and part-time work experience and for whether the individual was working full-time or part-time when the wage is measured, the coefficient on years of completed schooling is much smaller for each sample than the value reported in Table 3 or Table 4 . In fact, the coefficient is negative for the NLS72 sample of males. The reason is that individuals who enter the labor force directly have considerably more work experience than do individuals who graduate from college and this work experience is valued in the labor market.

18. Another possible explanation for why our estimates of the college-high school wage differential are lower than those of 
41

other researchers concerns our specification of educational attainment. We used a linear specification rather than a set of dichotomous variables (such as completed some college and fouryear college graduate) because this is the only specification for which we could compute an estimate of reliability. In fact, however, our estimate of the size of the college-high school wage differential for each sample is not very sensitive to the specification of years of completed schooling. To explore this, we compared fitted models with both a linear specification and a general specification using dummy variables under the assumption that the number of years of completed schooling was measured without error. For all four samples estimates of the collegehigh school wage differential from the general specification differed by no more than .005 from those obtained with the linear specification.

19. Bishop (1989b) found that a one standard deviation difference in test score was associated with a .19 standard deviation difference in earnings for household heads. This is larger than the effect sizes we report in this paper, even for 1980 high school graduates.

20. The reason for choosing a common math score differential ( 6.25 points) in discussing the sizes of the associated wage differentials in the four samples rather than using the standard deviations in the four samples is that we wanted the magnitudes of the wage differentials to be directly comparable. 
21. Each wage differential associated with a 6.25 point test score differential was calculated using the average wage for the relevant group as the starting point. We also fitted models in which high school seniors' scores on tests of reading and vocabulary were used as the skill measure. The pattern of results when the reading score is used as the skill measure is similar to the pattern using the math score, but the quantitative impacts on wages are smaller. For females, the vocabulary score is positively related to wages, with the coefficient approximately twice as large for 1980 graduates as for 1972 graduates. The vocabulary score is not a statistically significant predictor of wage for males in either sample.

When the math, reading, and vocabulary scores are included in the same model, the coefficients on the math score retain the pattern described in the text, but the coefficients on the reading and vocabulary scores become statistically insignificant for all four samples. This is due to the relative strength of the math score-wages relationship and the high correlations among the skill measures. Corrected for measurement error, the mathreading, math-vocabulary, and reading-vocabulary correlations are as follows: NLS72 males $(.75, .67, .83) ; \operatorname{HS\& B}$ males $(.81, .78$, $.90) ; \operatorname{NLS} 72$ females $(.76, .71, .87)$; and HA\&B females $(.81, .80$, .89) .

22. We use the 1988 poverty line because all wages are expressed in 1988 dollars. 
23. Table 5 presents the estimates with one more significant digit than is used in Tables 3 and 4 to facilitate sensitivity of the coefficients to model specification.

24. Another reason for interpreting the interaction cautiously is that Fuller's method of estimating the coefficient on a fallible interaction between two variables measured with error produces a slightly biased estimator of the impact of the interaction.

25. The estimates of the total impact of the test score on subsequent wages came from estimating a model with the same specification as Model b in Tables 3 and 4, except that the indicator of educational attainment was excluded. Thus, the coefficient on the math score reflects not only the direct effect of math score on earnings, but also the indirect effect stemming from the fact that students with higher math skills are more likely to participate in post-secondary education, which is itself rewarded in the labor market.

26. Had we done the calculation using the predicted total impacts of mathematics skills on the subsequent wages of males and females graduating from high school in 1972 rather than 1980 , the predicted effects of the growth in the college-high school skill differential on the growth in the college-high school wage differential would have been only half as large as those reported in the text.

27. In Japan, on the other hand, large employers maintain long term recruiting relationships with selected high schools in which 
teachers recommend selected students for jobs (Rosenbaum and Kariya, 1991) .

28. The coefficients reported in rows 2 and 3 of Table 6 were estimated using smaller subsamples than those used in estimating the coefficients reported in row 1 of Table 6 because the former subsamples included only individuals for whom a wage was available two years after high school graduation and six years after high school graduation. 29. While the positive coefficients on the math score are not significantly different from zero on conventional tests for the small subsamples used in estimating the results displayed in row 2 of Table 6 , the coefficients are significantly different from zero when the identical model is estimated for the larger subsamples that include all males whose highest educational attainment is a high school diploma and who have a legitimate wage value six years after high school graduation (row 1 of Table 6).

30. These results are also consistent with the studies of Lillard (1977) and Bound et al. (1986) who show that the impact of ability on earnings increases with age. 31. See Levy and Murnane (1992) for a discussion of the determinants of within-group variation in earnings. 
Figure 1. Fitted relationship between hourly wage at age-24 (in 1988 \$) and mathematics score for males, by year of high-school graduation.

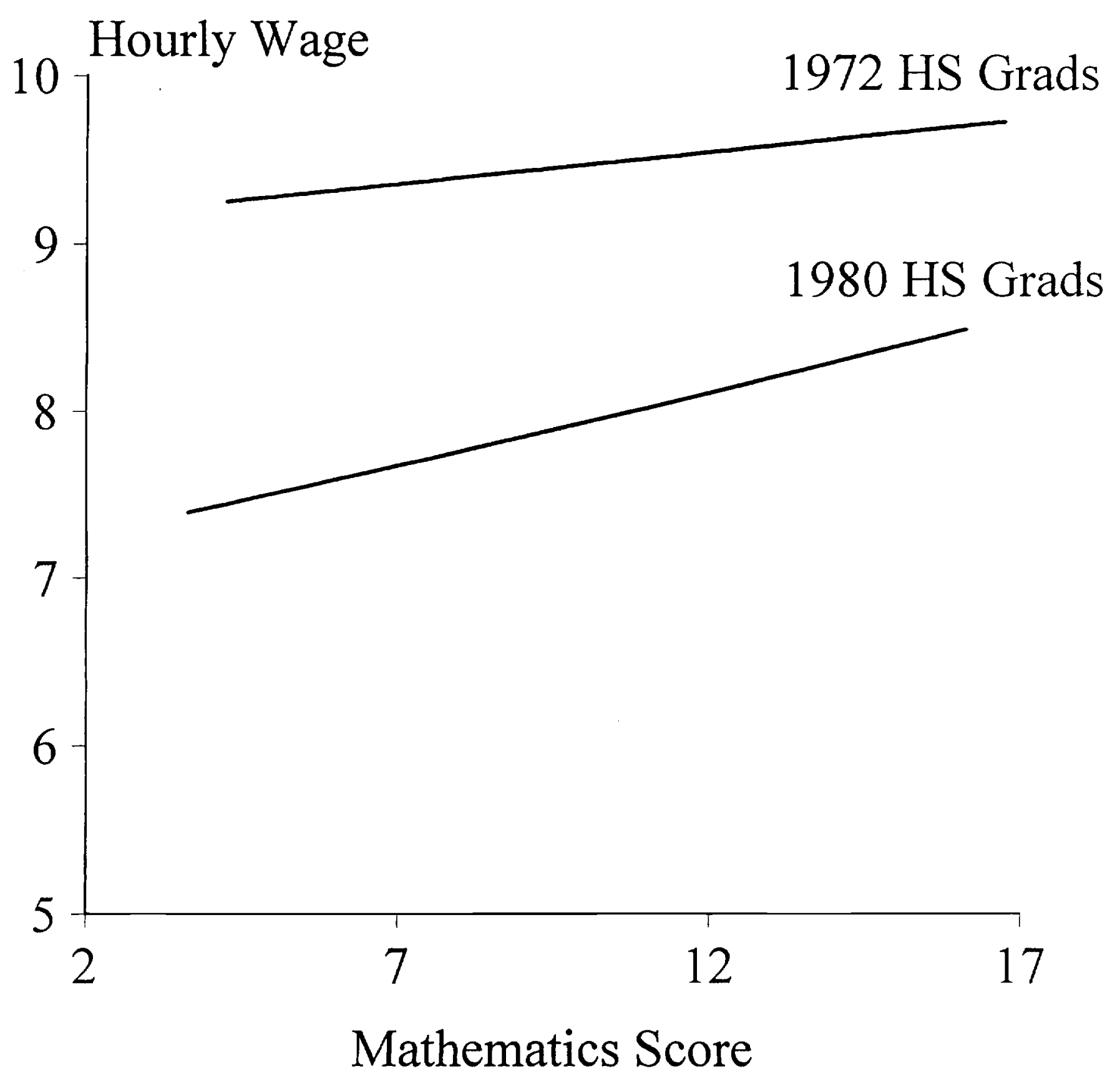


Figure 2. Fitted relationship between hourly wage at age-24 (in 1988 \$) and mathematics score for females, by year of high-school graduation.

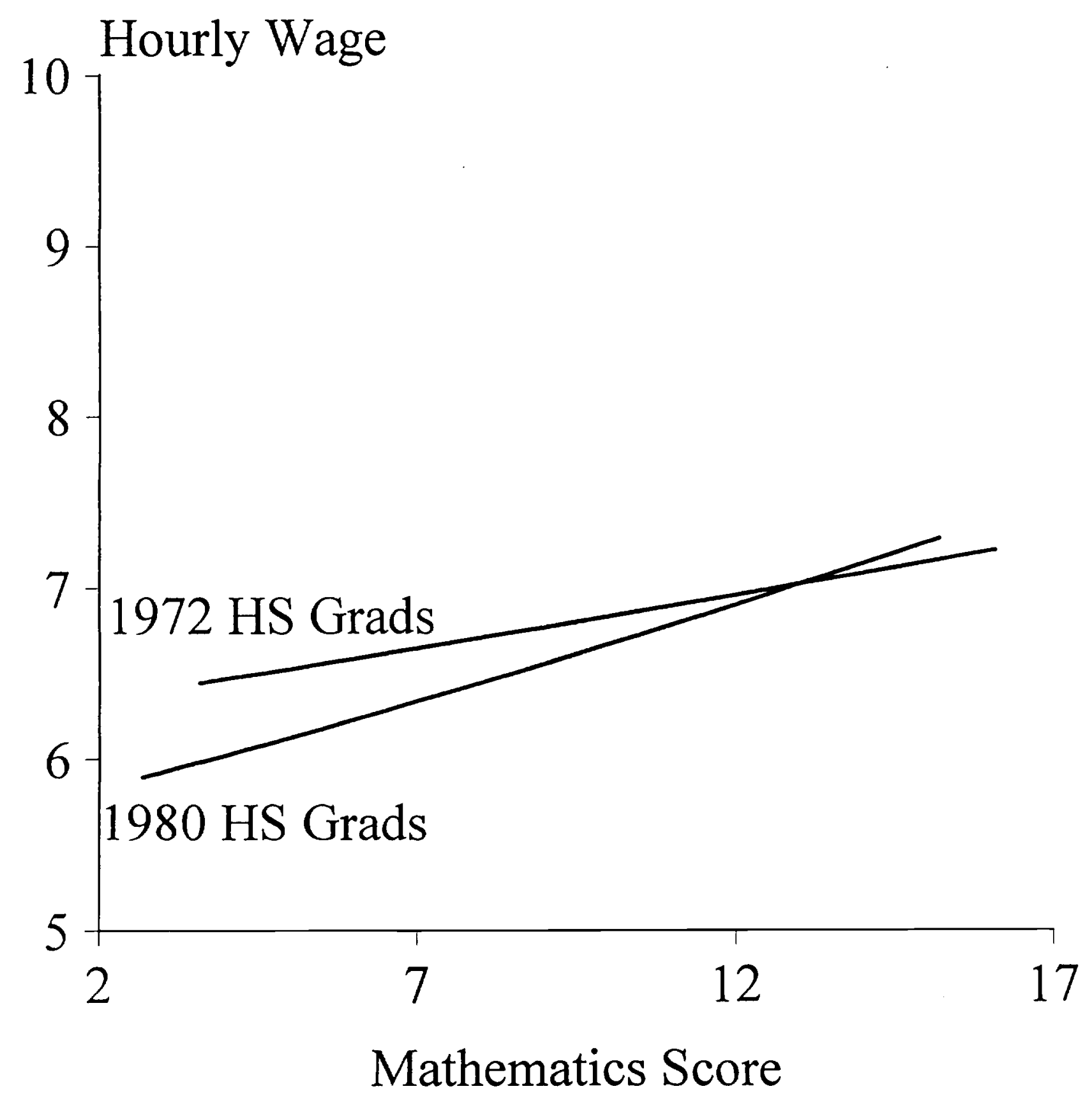

